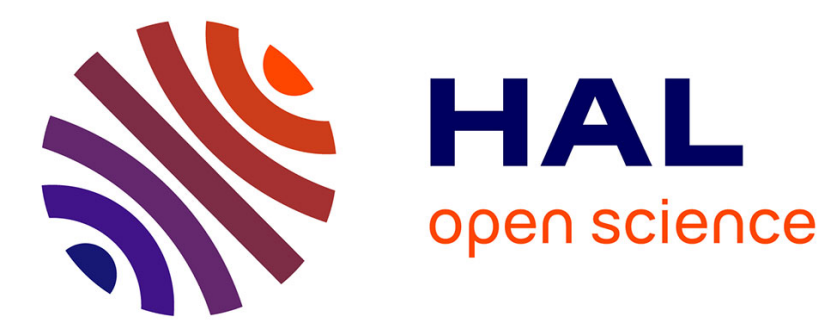

\title{
Are Individualistic Orientations Collectively Valuable in Group Negotiations?
}

\author{
Vidar Schei, Jørn K. Rognes, Carsten K. W. de Dreu
}

\section{To cite this version:}

Vidar Schei, Jørn K. Rognes, Carsten K. W. de Dreu. Are Individualistic Orientations Collectively Valuable in Group Negotiations?. Group Processes and Intergroup Relations, 2008, 11 (3), pp.371-385. 10.1177/1368430208090648. hal-00571693

\section{HAL Id: hal-00571693 https://hal.science/hal-00571693}

Submitted on 1 Mar 2011

HAL is a multi-disciplinary open access archive for the deposit and dissemination of scientific research documents, whether they are published or not. The documents may come from teaching and research institutions in France or abroad, or from public or private research centers.
L'archive ouverte pluridisciplinaire HAL, est destinée au dépôt et à la diffusion de documents scientifiques de niveau recherche, publiés ou non, émanant des établissements d'enseignement et de recherche français ou étrangers, des laboratoires publics ou privés. 


\title{
Are Individualistic Orientations Collectively Valuable in Group Negotiations?
}

\author{
Vidar Schei and Jørn K. Rognes \\ Norwegian School of Economics and Business Administration \\ Carsten K. W. De Dreu \\ University of Amsterdam
}

\begin{abstract}
This experiment examines how members' individualistic or cooperative motivational orientations affect the processes and outcomes of negotiating groups. A total of 228 students participated in a three-person negotiation simulation where motivational orientations were induced through written instructions and members were aware of each other's orientations. Results showed that groups with only cooperative members were more satisfied with their negotiations than were groups with other member compositions. Conversely, groups with only individualistic members achieved higher joint gains than did groups with other member compositions. Process analyses indicated that individualistic groups increased their integrative activities and decreased their distributive activities toward the end of their negotiations. Our results challenge the dominant view that individualistic orientations are detrimental for group processes and outcomes.
\end{abstract}

KEYWORDS cooperation, information, integrative and distributive processes, motivational orientation, negotiating groups

Groups often have to negotiate decisions because their members have conflicting interests and opinions. According to the negotiation literature (see De Dreu, Weingart, \& Kwon, 2000), agreements that best reconcile everyone's interests and generate better outcomes are reached when negotiators share a cooperative motivational orientation (they want to maximize both their own and others' outcomes). However, most of the research in this area involves dyadic negotiations, and although negotiations in dyads and groups share many characteristics, they also differ in important ways (Bazerman, Mannix, \& Thompson, 1988). For example, challenges associated with complexity in information, interpersonal relations, procedures, and strategies all increase when there are three or more negotiators, rather than just two (see Kramer, 1991).

\footnotetext{
Author's note

Address correspondence to Vidar Schei, Norwegian School of Economics and Business Administration, Department of Strategy and Management, Breiviksveien 40, N-5045 Bergen, Norway [email: vidar.schei@nhh.no]
} 
Unfortunately, research on motivational orientations in negotiating groups is limited, and the few studies that have been done largely ignore the fact that members of the same group can have different motivational orientations. Mixed orientations are especially likely in groups that are diverse in other ways as well (Brett, 2001). Furthermore, group members may or may not be aware of one another's motivational orientations. For example, members of management teams or cross-functional teams inside organizations, and members of business teams operating between organizations (e.g.joint ventures), may know much about one another from previous encounters. Rumours, gossip, and reputations may also allow people to make reasonable assumptions about one another's motivational orientations. Yet the effects of knowledge about the motivational orientations of others in negotiating groups have seldom been studied.

The available research evidence thus reveals little about negotiation processes and outcomes in groups whose members differ in their motivational orientations and are aware of those differences. We thus designed an experiment to investigate such groups. We focused on individualistic and cooperative motivational orientations because they seem to be the most common (Pruitt \& Carnevale, 1993) and have been found to have substantial impact on dyadic negotiations (De Dreu, Weingart et al., 2000). We examined motivational orientations stemming from situational characteristics (states) rather than individual dispositions (traits), because situational characteristics are easier to influence from a managerial point of view and are related more strongly to organizational settings (e.g. climate factors, incentive systems). Finally, we included both objective and subjective outcome measures because research has shown that negotiators consider more than just material gains and losses (Curhan, Elfenbein, \& Xu, 2006), and because there is often a disconnect between the quality of negotiated agreements and the satisfaction parties derive from them (Galinsky, Mussweiler, \& Medvec, 2002).

The effects of motivational orientations on negotiation processes and outcomes can be understood using Dual Concern Theory (Pruitt \&
Rubin, 1986). This theory suggests that a negotiator's behavior is determined by two motives, namely the person's concerns for (a) his or her own outcome and (b) the outcomes of others. When a negotiator has high concern for the outcomes of both the self and others (similar to a 'cooperative' orientation), he or she behaves in an integrative way, displaying problem-solving behavior by exchanging information in a trustworthy manner. But when a negotiator has high self-concern and low concern for others (similar to an 'individualistic' orientation), he or she behaves in a distributive way, displaying contentious behavior by using pressure tactics and persuasive argumentation to gain concessions. Consistent with Dual Concern Theory, a meta-analytic review by De Dreu, Weingart et al. (2000) found that pairs of negotiators with cooperative orientations, relative to pairs with individualistic orientations, indeed engaged in more integrative behavior and less distributive behavior. These behaviors, in turn, led to higher joint outcomes in cooperative rather than individualistic dyads.

The integrative behavior of cooperators and the distributive behavior of individualists may be even greater when negotiators are aware of each other's motivational orientations. For example, when cooperators negotiate with each other, knowing that they share a cooperative orientation may make it easier to reveal their true preferences and opinions and to trust the information that others give them. Greater information exchange, combined with higher levels of trust, may stimulate integrative processes and thereby produce higher joint gain and satisfaction. Conversely, when individualists negotiate with each other, knowing that they share an individualistic orientation may promote 'power games'-negotiators demand concessions from each other, without making concessions themselves. Such tactics may stimulate distributive processes that lead to dissatisfaction and lower joint gains.

All in all, research on dyadic negotiation suggests that joint gains will be better (Hypothesis 1), satisfaction will be greater (Hypothesis 2), and the negotiation process will be more integrative and less distributive (Hypothesis 3) when 
there are more cooperative members in a negotiating group.

But research on dyads could be misleading when it comes to negotiating groups. For example, group negotiations impose extra challenges on participants (see Bazerman et al., 1988; Kramer, 1991). In dyadic negotiations, a person can focus on the behavior of the other party and concentrate his or her energy on influencing that person. In groups, however, it is also necessary to consider other parties, who may have different strategies and may not all respond to one's behavior in the same way (Brett, 1991). In groups, there is also a potential for coalition formation, which cannot occur in dyads (Mannix, 1994; Ten Velden, Beersma, \& De Dreu, 2007). These differences suggest that our earlier hypotheses might be too simplistic. For example, having just one individualistic group member might be enough to keep everyone else on their toes (cf. Kelley \& Stahelski, 1970), or that person might be isolated by a coalition of cooperative members (cf. Brett, 1991).

Recent research on the role of motivational orientations in group negotiations has indeed produced complex results. Although cooperative rather than individualistic group members do show more integrative processes, less distributive processes, and better satisfaction and joint gains (Beersma \& De Dreu, 2002, 2005; Weingart, Bennett, \& Brett, 1993), a close examination of this work shows that such findings only occur under specific circumstances. For example, Weingart et al. (1993) found that cooperative groups do better than individualistic groups only when people are instructed to consider issues sequentially. When people consider issues simultaneously (as they do in many real life situations), individualistic groups do as well as cooperative groups. Under these circumstances, individualistic negotiators may be unwilling to make unilateral concessions because they don't trust others to make comparable concessions in response. Thus, they compromise rather than integrate. Similarly, Beersma and De Dreu (2002) found that cooperative groups outperform individualistic groups only when the structure of the negotiation is asymmetrical (two parties have compatible preferences that are incompatible with the preferences of other parties). When the structure is symmetrical (as it is in many real life situations), the outcomes of cooperative groups are not significantly better than those of individualistic groups. When the structure of a negotiation is asymmetrical, individualists may get locked into coalitions and not dynamically trade issues.

Moreover, some studies have found no outcome differences at all across different group compositions (Schei \& Rognes, 2005; Weingart, Brett, \& Olekalns, 2002). In their research on three-person negotiating groups, for example, Schei and Rognes (2005) found comparable outcomes in cooperative, individualistic, and mixed groups. Similarly, Weingart et al. (2002) found no outcome differences among fourperson groups composed of all cooperative, all individualistic, or mixed members. Weingart and her colleagues also examined the negotiation processes in their groups and found more integrative behavior in groups that contained more cooperative members. Finally, a few researchers have even found that negotiating groups with more individualistic members achieve better outcomes. For instance, Shapiro and Rognes (1996) measured the conflict orientations of group members and found that a 'dominating' style (similar to an individualistic motivational orientation) improved group outcomes.

So, what other predictions could be made about the effects of motivational orientations on the outcomes of negotiating groups? The findings just cited suggest that a more careful analysis is needed. Groups that contain only cooperative members may focus heavily on cooperation and thus satisfice (Simon, 1957), choosing the first acceptable solution that is proposed, rather than searching for an optimal solution, which can be hard to find (Kramer, 1991). An emphasis on cooperation may also lead group members to abandon their individual interests, believing that this will help the group. To develop high quality agreements, however, it may be necessary for negotiators to remember their personal interests and not yield uncritically (Pruitt, 1983). Indeed, yielding behavior can be detrimental for cooperators. A meta-analytical review by De Dreu, Weingart et al. (2000) showed 
that cooperative negotiators only reached mutually beneficial outcomes when they had high resistance to yielding. When resistance to yielding was low, cooperative negotiators engaged in less problem-solving, were more contentious, and achieved lower joint outcomes. If cooperative group members have information about one another's orientations, then tendencies toward satisficing may be even higher than when such information is absent.

If cooperative negotiating groups can perform poorly because of their tendency to compromise and satisfice, then individualistic groups may perform well because of enlightened selfinterest (Rubin, 1991). Individualistic members of groups often use arguments to persuade others to make concessions. Knowing that other group members are also individualistic, however, may lead a negotiator to doubt his or her ability to exploit others. If other negotiators are indeed unlikely to make concessions, then the only way to get a high personal outcome is to enlarge the pie through integrative behavior. An escalating integrative process (Olekalns, Brett, \& Weingart, 2003), coupled with an energetic search for good personal outcomes, may drive individualistic groups toward optimal solutions. Indeed, work by Harinck and De Dreu (2004) showed that people who experience temporary impasses in the first part of their negotiations often realize that a change in behavior is needed to accomplish their goals.

Integrative processes and good outcomes may be difficult to achieve when members are aware of differences in their motivational orientation. Individualistic members may try to take advantage of people they know are cooperatively oriented and cooperative members may try to protect themselves against such exploitation. These groups may thus experience low joint outcomes and dissatisfaction because they lack the integrative process usually associated with optimal agreements. Indeed, Schei and Rognes (2003) found that in mixed dyads (cooperators versus individualists), where the individualists knew that their opponents were cooperatively motivated, integrative activities, perceived negotiation quality, and joint outcomes were all low.
Thus, as a set of alternatives to our earlier hypotheses, we propose that joint gains will be maximized when all group members are individualists (Hypothesis 4), satisfaction will be maximized when all group members are cooperators (Hypothesis 5), and the negotiation process will be more integrative and less distributive toward the end of a negotiation when all group members are individualists (Hypothesis 6).

\section{Method}

\section{Sample}

We studied 228 undergraduate business students ( $35 \%$ female, mean age $=21$ years $)$ enrolled in an organizational behavior course. The participants were randomly assigned to have a cooperative or an individualistic orientation. And they were each assigned to negotiate in a three-person group that was either (1) cooperative $(n=20)$, with three cooperators (CCC); (2) cooperative majority $(n=19)$, with two cooperators and one individualist (CCI); (3) individualistic majority $(n=19)$, with one cooperator and two individualists (CII); or (4) individualistic $(n=18)$, with three individualists (III).

\section{Negotiation task}

We used a negotiation task identical to the one used by Schei and Rognes (2005). Three people negotiated the construction of a joint office complex for a business partnership involving an airline company, an insurance company, and a consulting company. The payoff matrices are shown in Table 1. Five issues had to be negotiated: (1) move-in date, (2) geographical location of the building, (3) architectural design, (4) distribution of maintenance costs, and (5) establishment of joint service functions. The group had to resolve all five issues to reach an agreement. The negotiation simulation was symmetric, giving all the members both the same maximum number of achievable points and equal chances of earning those points. The task had both integrative and distributive issues. The three integrative issues (Issues 2, 3, and 5) allowed for joint gain through logrolling (cf. Mannix, Thompson, \& Bazerman, 1989). The two distributive issues (Issues 1 and 4) 
made the symmetry in the payoff matrix less obvious and thus raised the level of potential conflict in the groups.

\section{Manipulation of motivational orientations}

We followed previous research on motivational orientations in negotiation and manipulated the two orientations through written instructions. The manipulations were presented as instructions to negotiators from the management of their companies (cf. Weingart et al., 1993). In the individualistic condition, participants read that their primary goal was to maximize own outcome. In the cooperative condition, participants read that their primary goal was to maximize own and group outcome. We examined the effects of these instructions by asking the participants to indicate in the post-negotiation questionnaire which primary objective they had during the negotiation: (a) maximize own outcome, (b) maximize own and group outcome, or (c) other (cf. Weingart et al., 1993). The instructions had a significant impact on the participant's responses $\left(\chi^{2}(2, N=228)=152.77, p<.001\right)$. In the cooperative condition, $92 \%$ of the subjects answered 'maximize own and group outcome', and in the individualistic condition, $86 \%$ of the subjects answered 'maximize own outcome'. Consistent with earlier studies of mixed motivational orientations (e.g. Schei \& Rognes, 2003, 2005), we included in our primary analyses only those groups where all members answered the manipulation check question correctly ( $n=16,17,15,12$ groups in the CCC,

Table 1. Payoff matrices

\begin{tabular}{|c|c|c|c|c|c|}
\hline Issues & Alternatives & $\begin{array}{l}\text { Airline } \\
\text { company }\end{array}$ & $\begin{array}{l}\text { Insurance } \\
\text { company }\end{array}$ & $\begin{array}{c}\text { Consulting } \\
\text { company }\end{array}$ & Sum \\
\hline \multirow[t]{4}{*}{ Issue 1} & A & 25 & 0 & 50 & 75 \\
\hline & B & 25 & 25 & 25 & 75 \\
\hline & $\mathrm{C}$ & 0 & 50 & 25 & 75 \\
\hline & $\mathrm{D}$ & 50 & 25 & 0 & 75 \\
\hline \multirow[t]{5}{*}{ Issue 2} & $\mathrm{~A}$ & 150 & 12.5 & 25 & 187.5 \\
\hline & B & 200 & 0 & 0 & 200 \\
\hline & $\mathrm{C}$ & 100 & 25 & 50 & 175 \\
\hline & $\mathrm{D}$ & 0 & 50 & 100 & 150 \\
\hline & $\mathrm{E}$ & 50 & 37.5 & 75 & 162.5 \\
\hline \multirow[t]{5}{*}{ Issue 3} & A & 50 & 100 & 0 & 150 \\
\hline & B & 0 & 0 & 200 & 200 \\
\hline & $\mathrm{C}$ & 37.5 & 75 & 50 & 162.5 \\
\hline & $\mathrm{D}$ & 12.5 & 25 & 150 & 187.5 \\
\hline & $\mathrm{E}$ & 25 & 50 & 100 & 175 \\
\hline \multirow[t]{4}{*}{ Issue 4} & A & 0 & 100 & 50 & 150 \\
\hline & B & 50 & 0 & 100 & 150 \\
\hline & $\mathrm{C}$ & 50 & 50 & 50 & 150 \\
\hline & $\mathrm{D}$ & 100 & 50 & 0 & 150 \\
\hline \multirow[t]{5}{*}{ Issue 5} & A & 100 & 0 & 50 & 150 \\
\hline & B & 75 & 50 & 37.5 & 162.5 \\
\hline & $\mathrm{C}$ & 50 & 100 & 25 & 175 \\
\hline & $\mathrm{D}$ & 25 & 150 & 12.5 & 187.5 \\
\hline & $\mathrm{E}$ & 0 & 200 & 0 & 200 \\
\hline Minimum payoff & & 0 & 0 & 0 & 675 \\
\hline Maximum payoff & & 500 & 500 & 500 & 825 \\
\hline
\end{tabular}

Note: Negotiators saw only their own payoffs, and were not allowed to exchange preference charts. 
CCI, CII, and III conditions, respectively, for a total of 180 individuals). Exploratory analyses that included data from all of the groups produced results similar to those from the primary analyses.

\section{Procedure}

The experiment was conducted during a class meeting in the course. Each negotiator received confidential role instructions, manipulation instructions, a profit schedule that showed the individual earnings associated with different possible alternatives, and information about the motivational orientations-cooperative or individualistic - that could be expected from their opponents. The participants had 15 minutes to read their role information and prepare for the negotiations. The groups were allowed to negotiate for 45 minutes. Finally, participants answered the post-negotiation questionnaire, which contained background information and the manipulation check and the process measures. Afterwards, participants were debriefed, thanked for their help, and dismissed.

\section{Measures}

Joint outcomes We measured joint outcomes by examining (a) joint sums and (b) Pareto efficiency. We chose to include both measures because they are conceptually different and prior research on group negotiation has shown that they can produce different results (De Dreu, Giebels, \& Van de Vliert, 1998; Weingart et al., 1993). Joint sum was measured as the sum of the profits achieved by the three negotiators in a group. For example, if a group's members agreed on alternative A for all five of the issues, then the joint sum for that group would be 712.5. The range of joint sums was 675 (minimum) to 825 (maximum) points. Pareto efficiency related actual agreements to Pareto optimal settlements. A Pareto optimal agreement implies that the group has reached an agreement that cannot be improved unless one of the group members accepts a lower individual outcome. We developed an index, based on work by Tripp and Sondak (1992), who measured the number of possible agreements that were Pareto superior to the solution chosen by each group. Hence, we looked at each group's actual agreement and counted the number of possible agreements that would have produced a better individual outcome for at least one of the group members, without lowering the individual outcomes for any other members. This measure was positively skewed (1.78), so we did a log transformation to normalize its distribution (skewness after transformation $=0.12$ ). We then standardized the variable and reversed it so that higher values indicated greater Pareto efficiency.

Satisfaction We measured satisfaction as the average of three items in the post-negotiation questionnaire: 'How satisfied are you with the negotiation outcome?', 'How satisfied are you with the negotiation process?', and 'To which degree is the group agreement acceptable to you?'. Responses were made on a 5-point Likertscale ranging from 1 (very dissatisfied) to 5 (very satisfied). The reliability coefficient of the overall satisfaction scale was $\alpha=.74$. To measure satisfaction at the group level, we calculated the inter-rater agreement index for multiple items (James, Demaree, \& Wolf, 1984, 1993). Average inter-rater agreement was .83, and did not differ significantly across the group composition conditions. This is well above the suggested benchmark of .70 (George \& Bettenhausen, 1990), and justifies the use of satisfaction as a group variable (George \& James, 1993). Finally, after inspecting for outliers on the satisfaction scale, the score on one item in one group was removed because it had a standardized value above $|3|$.

Negotiation processes We measured the negotiation process using several other items on the post-negotiation questionnaire. The relevant items are shown in Table 2. Responses were made on a 5-point Likert-scale ranging from 1 (to a low extent) to 5 (to a high extent). The participants were asked to evaluate both integrative activities (e.g. information exchange, trust) and distributive activities (e.g. pressure tactics, argumentation). A principal component analysis with oblique rotation revealed the two expected factors (integrative 
and distributive), both with eigenvalues larger than one and explaining 30.2 and $24.1 \%$ of the variance, respectively. All of the items in Table 2 loaded above (or close to) .50 on just one of the factors.

Consistent with the procedure used by Schei and Rognes (2003), group members discussed together each of the items in Table 2 before giving their individual responses. Group members typically gave the same response, making the inter-rater agreement index $\approx 1$. Also consistent with Schei and Rognes (2003), the participants first answered questions regarding the overall negotiation process, and then the process in each of three phases. Participants were told that Phase 1 should be seen as about the first $25 \%$ of the time used, Phase 2 as about the next $50 \%$ and Phase 3 as about the last 25\%. These roughly correspond to the initiation, problemsolving, and resolution phases uncovered in past work on negotiation (see Holmes, 1992). Inspecting for outliers showed that in three cases integrative items had standardized scores above |3|, so the score on these items for the respective groups were therefore removed. The reliability coefficients were $\alpha=.66$ for the integrative activities scale and $\alpha=.61$ for the distributive activities scale. We found these coefficients acceptable, given the broad and somewhat formative nature of the measures.

\section{Results}

\section{Descriptive statistics and correlations}

Table 3 shows descriptive statistics and correlations for the measures. Group composition, as measured by number of individualistic members (0 to 3 ), was positively correlated with joint sums and Pareto efficiency, and negatively correlated with satisfaction. Integrative and distributive activities showed relatively low correlations with group composition and group outcome variables. The two outcome measures, joint sums and Pareto efficiency were so highly correlated with one another that they were essentially the same variable. Therefore, in the subsequent

Table 2. Factor analysis for measures of the negotiation process

\begin{tabular}{lcr}
\hline Process items & Integrative & Distributive \\
\hline 1. Not sure that the truth was told (reverse-coded) & .79 & -.09 \\
2. Trusted the information exchange & .77 & -.04 \\
3. Communicated our interests clearly & .68 & .33 \\
4. Exchanged information about interests/priorities & .52 & -.02 \\
5. Pressed to get individual interests through & .09 & .82 \\
6. Conflict among members & -.35 & .82 \\
7. Argumentation & .11 & $\mathbf{. 4 9}$ \\
\hline
\end{tabular}

Note: The numbers shown are factor loadings.

Table 3. Means, standard deviations, and correlations

\begin{tabular}{|c|c|c|c|c|c|c|c|}
\hline Variable & Mean & $S D$ & 1 & 2 & 3 & 4 & 5 \\
\hline $\begin{array}{l}\text { 1. Group composition (no. of } \\
\text { individualists) }\end{array}$ & 2.42 & 1.09 & 1 & & & & \\
\hline 2. Joint sums & 758 & 42 & $.38 * *$ & 1 & & & \\
\hline 3. Pareto efficiency & 0.00 & 1.00 & $.38 * *$ & $.94 * * *$ & 1 & & \\
\hline 4. Satisfaction & 3.49 & 0.33 & $-.37 * *$ & .06 & .04 & 1 & \\
\hline 5. Integrative activities (overall) & 4.11 & 0.57 & -.09 & .18 & .04 & .14 & 1 \\
\hline 6. Distributive activities (overall) & 3.50 & 0.61 & .10 & -.06 & .03 & -.09 & .08 \\
\hline
\end{tabular}

$* * p<.01 ; * * * p<.001$.

Note: $n=60$ groups. 
analyses, we report the results for joint sums, which is the most widely used outcome measure. Using Pareto efficiency as a measure of joint outcome yielded similar results. Finally, we checked for gender effects, but found none.

\section{Group outcomes}

We first examined the effects of group composition on group outcomes. Table 4 shows means, standard deviations, and the results from an analysis of variance (ANOVA), along with pairwise comparisons. Group composition had a significant effect on joint sums $(F(3,56)=7.51$, $\left.p<.001, \eta^{2}=.29\right)$. Individualistic groups achieved higher joint sums $(M=802)$ than did cooperative groups $(M=750)$, cooperative majority groups $(M=740)$, or individualistic majority groups $(M=749)$. Pairwise comparisons showed that joint sums were significantly higher in the individualistic groups than in groups with any of the other three compositions $(p<.01)$, with no significant differences among the groups with those other compositions. These results do not support Hypothesis 1, but they do support the alternative, Hypothesis 4.

Group also had a significant effect on satisfaction $\left(F(3,56)=4.98, p<.01, \eta^{2}=.21\right)$. Members of cooperative groups were more satisfied $(M=3.74)$ than members of individualistic groups $(M=3.36)$, individualistic majority groups $(\mathrm{M}=3.44)$, or cooperative majority groups $(M=3.36)$. Pairwise comparisons showed that satisfaction was significantly higher in cooperative groups than in groups with each of the other compositions $(p<.01)$. No other comparisons were significant. Thus, the results do not support Hypothesis 2, but they do support the alternative, Hypothesis 5.

\section{Negotiation processes}

We first examined how group composition influenced integrative activities, such as those involving information exchange and trust. Group composition did not affect these activities overall $(F(3,56)=0.32, n s)$. The means across group composition conditions are shown in Table 5. To analyze integrative activities further, we did a 4 (Compositions) $\times 3$ (Phases) ANOVA with Phases as repeated measures. Phase had a significant linear impact on integrative activities $\left(F(1,56)=10.33, p<.01, \eta^{2}=.16\right)$. As Table 5 shows, integrative activities increased over time. The interaction between Composition and Phase was also significant $(F(3,56)=6.68$, $\left.p<.001, \eta^{2}=.26\right)$. The means show that this interaction effect occurred because the individualistic groups (III) - unlike the other group compositions-had a very strong increase in integrative activities during their negotiations. They had the least integrative activity in Phase 1 and the most integrative activity in Phase 3. Analyzing the integrative negotiation process (from Phase 1 to Phase 2 to Phase 3 ) in each of the four compositions showed that individualistic groups were the only ones whose integrative activities increased significantly throughout the three phases $(F(1,11)=16.24, p<.01$, $\left.\eta^{2}=.60\right)$. In these groups there were more

Table 4. ANOVA results for group outcomes across group compositions

\begin{tabular}{|c|c|c|c|c|c|c|}
\hline \multirow[b]{2}{*}{ Group outcomes } & \multicolumn{4}{|c|}{ Group composition } & \multirow[b]{2}{*}{$F(3,56)$} & \multirow[b]{2}{*}{ Eta-square } \\
\hline & CCC & CCI & CII & III & & \\
\hline \multicolumn{7}{|l|}{ Joint sums } \\
\hline $\begin{array}{l}\text { Mean } \\
S D\end{array}$ & $\begin{array}{c}750_{\mathrm{a}} \\
44\end{array}$ & $\begin{array}{c}740_{a} \\
44\end{array}$ & $\begin{array}{c}749_{a} \\
23\end{array}$ & $\begin{array}{c}802_{b} \\
33\end{array}$ & $7.51 * * *$ & .29 \\
\hline \multicolumn{7}{|l|}{ Satisfaction } \\
\hline $\begin{array}{l}\text { Mean } \\
S D\end{array}$ & $\begin{array}{l}3.74_{\mathrm{a}} \\
0.29\end{array}$ & $\begin{array}{l}3.36_{\mathrm{b}} \\
0.37\end{array}$ & $\begin{array}{l}3.44_{\mathrm{b}} \\
0.25\end{array}$ & $\begin{array}{l}3.36_{\mathrm{b}} \\
0.33\end{array}$ & $4.98 * *$ & .21 \\
\hline
\end{tabular}

$* * p<.01 ; * * * p<.001$.

Notes: Means in the same row that do not share subscripts differ at $p<.01$. CCC $=$ cooperative groups, $\mathrm{CCI}=$ cooperative majority groups, $\mathrm{CII}=$ individualistic majority groups, and III = individualistic groups. 
Table 5. Means and standard deviations for integrative and distributive activities across group compositions and negotiation phases

\begin{tabular}{|c|c|c|c|c|c|c|c|c|}
\hline \multirow[b]{2}{*}{ Group composition } & \multicolumn{4}{|c|}{ Integrative activities } & \multicolumn{4}{|c|}{ Distributive activities } \\
\hline & Phase 1 & Phase 2 & Phase 3 & Overall & Phase 1 & Phase 2 & Phase 3 & Overall \\
\hline \multicolumn{9}{|l|}{ Cooperative (CCC) } \\
\hline Mean & 3.99 & 4.19 & 4.26 & 4.23 & 3.27 & 3.46 & 3.33 & 3.38 \\
\hline$S D$ & 0.61 & 0.53 & 0.58 & 0.56 & 0.80 & 0.86 & 0.72 & 0.73 \\
\hline \multicolumn{9}{|c|}{ Cooperative majority (CCI) } \\
\hline Mean & 4.10 & 4.03 & 4.08 & 4.05 & 3.10 & 3.70 & 3.56 & 3.47 \\
\hline$S D$ & 0.66 & 0.64 & 0.57 & 0.65 & 0.72 & 0.48 & 0.58 & 0.44 \\
\hline \multicolumn{9}{|c|}{ Individualistic majority (CII) } \\
\hline Mean & 3.99 & 4.02 & 3.98 & 4.04 & 3.22 & 3.93 & 3.53 & 3.69 \\
\hline$S D$ & 0.68 & 0.59 & 0.66 & 0.64 & 0.67 & 0.82 & 0.79 & 0.61 \\
\hline \multicolumn{9}{|l|}{ Individualistic (III) } \\
\hline Mean & 3.55 & 4.20 & 4.52 & 4.10 & 3.58 & 3.75 & 2.92 & 3.45 \\
\hline$S D$ & 0.83 & 0.47 & 0.40 & 0.53 & 0.77 & 0.43 & 1.07 & 0.49 \\
\hline \multicolumn{9}{|l|}{ Total } \\
\hline Mean & 3.91 & 4.11 & 4.19 & 4.07 & 3.29 & 3.71 & 3.34 & 3.45 \\
\hline$S D$ & 0.70 & 0.56 & 0.58 & 0.61 & 0.74 & 0.65 & 0.79 & 0.73 \\
\hline
\end{tabular}

integrative activities in Phase 2 than in Phase 1 $(p<.01)$, and more in Phase 3 than in Phase 2 $(p=.05)$. Indeed, individualistic groups ended up having more integrative activities in Phase 3 than did both kinds of mixed orientation groups $(p<.05)$, but not significantly more than cooperative groups.

Next, we examined how group composition affected distributive activities, such as those involving pressure tactics and argumentation. Group composition did not affect these activities overall $(F(3,56)=0.76, n s)$. The means across compositions are shown in Table 5. To analyse distributive activities further, we did another 4 (Compositions) $\times 3$ (Phases) ANOVA with phases as repeated measures. Phase did not have a linear effect on distributive activities $(F(1,56)=0.14, n s)$, but it did have a strong quadratic effect $(F(1,56)=21.35, p<.001$, $\left.\eta^{2}=.28\right)$. The means in Table 5 show a reversed U-shaped pattern-distributive activities increased from Phase 1 to Phase 2 and then decreased in Phase 3. The interaction between Composition and Phase was also significant $(F(3,56)=4.65$, $\left.p<.01, \eta^{2}=.15\right)$. The interaction effect occurred because the individualistic groups (III) —unlike the other groups-reduced their distributive activities from the first to the final phase. Although their distributive activities were highest (among all the composition conditions) at first, individualistic groups finished with the lowest distributive activities. Analyzing the distributive negotiation process (from Phase 1 to Phase 2 to Phase 3 ) in each of the four compositions showed that the individualistic groups (and to a lesser degree, the individualistic majority groups) were the only compositions with a significant decrease in distributive activities from Phase 2 to Phase $3(p<.05)$. Importantly, individualistic groups ended up having less distributive activities in Phase 3 than did both kinds of mixed groups $(p<.05)$, but not significantly less than the cooperative groups.

Taken altogether, the results for integrative and distributive activities do not support Hypothesis 3, but they do support the alternative, Hypothesis 6.

\section{Additional analyses}

In addition to testing the various hypotheses, we also examined the relationship between negotiation processes and joint sums using regression analyses. The results are shown in Table 6. We ran four separate regressions, examining both 
Table 6. Regression analyses of joint sums on negotiation processes

\begin{tabular}{lcccc}
\hline Negotiation processes & Phase 1 & Phase 2 & Phase 3 & Overall \\
\hline Integrative activities & -.09 & .17 & $.36^{* *}$ & .18 \\
Distributive activities & .12 & .07 & $-.35^{* *}$ & -.07 \\
$R^{2}$ & .02 & .03 & .27 & .04 \\
$F$ for $R^{2}$ & 0.70 & 0.99 & $10.72^{* * *}$ & 1.05 \\
\hline
\end{tabular}

$* * p<.01 ; * * * p<.001$.

Notes: Regression analyses were run separately for the overall process and for each phase. Standardized coefficients are shown.

the overall negotiation process and each of the three negotiation phases. The overall negotiation processes had no significant effect on joint sums $\left(R^{2}=.04, n s\right)$, nor did the negotiation processes in the two first phases (Phase 1: $R^{2}=.02$, ns, Phase 2: $\left.R^{2}=.03, n s\right)$. However, negotiation processes in Phase 3 did have a significant impact on joint sums $\left(R^{2}=.27, p<.001\right)$. Integrative activities in that phase had a significant positive effect on joint sums $(\beta=.36, p<.01)$, whereas distributive activities had a significant negative effect $(\beta=-.35, p<.01)$. We also inspected the effects of negotiation processes on joint sums for each of the four group compositions separately. The results mainly paralleled the overall pattern, except that the negotiation processes in Phase 3 had very little impact on joint sums in the individualistic majority groups, and the positive effects of integrative activities on joint sums in Phase 3 were especially strong in the individualistic groups $(\beta=.71, p<.01)$.

Finally, we examined mediation effects. Mediation analyses may help us understand the mechanism through which motivational orientation affects joint sums. Thus, we believed that the high joint sums achieved by the individualistic groups could be explained by these groups being high on integrative activities and low on distributive activities. As noted earlier, group composition (the independent variable) had significant effects on both the dependent variable (joint sums) and on the mediator (negotiation processes), and negotiation processes (in Phase 3) significantly affected joint sums. The remaining question is how group composition and the negotiation processes in Phase 3 mutually affected joint sums. We did hierarchical analyses to test for mediation, following the recommendations outlined by Kenny, Kashy, and Bolger (1998). Joint sums were regressed on group composition and negotiation processes-entering Composition in Step 1 and entering Phase 3 activities, (integrative and distributive) in Step 2. The results are shown in Table 7. Entering the process variables (integrative and distributive) into the model increased $R^{2}$ significantly from .15 to $.37(F(2,56)=9.62, p<.001)$. Integrative activities had a positive effect on joint sums $(\beta=.34, p<.01)$, and distributive activities had a negative $(\beta=-.31, p<.01)$ effect. However, the significant effect of group composition in Step $1(\beta=.38, p<.01)$ did not disappear when the process variables were entered in Step 2 $(\beta=.31, p<.01)$, and Sobel tests produced nonsignificant results. Thus, no evidence for full mediation was found. Group composition and negotiation processes apparently codetermine joint sums.

Table 7. Hierarchical regression analyses of joint sums

\begin{tabular}{lcc}
\hline Variable & Step 1 & Step 2 \\
\hline Group composition & $.38^{* * *}$ & $.31^{* *}$ \\
Integrative activities in & & $.34^{* * *}$ \\
$\quad$ Phase 3 & & \\
Distributive activities in & & $-.31^{* *}$ \\
$\quad$ Phase 3 & & \\
$R^{2}$ & .15 & .37 \\
$F$ for $R^{2}$ & $9.88^{* *}$ & $10.69^{* * *}$ \\
$\Delta R^{2}$ & & .22 \\
$F$ for $\Delta R^{2}$ & & $9.62^{* * *}$ \\
\hline
\end{tabular}

$* * p<.01 ; * * * p<.001$.

Note: Standardized coefficients are shown. 


\section{Discussion}

Cross-functional teams and heterogeneous project groups are pervasive, both inside and between organizations. When the members of such groups negotiate decisions, they are often aware of whether their teammates have individualistic or cooperative orientations. We have contributed to the negotiation literature by conducting the first experiment that examines how the mixture of motivational orientations in a group affects negotiation processes and outcomes when members are aware of each other's orientations. We found that groups containing only cooperative members were more satisfied with their negotiations than were groups with other compositions. In contrast, we found that groups containing only individualistic members achieved higher joint sums than did groups with other motivational compositions. Finally, individualistic groups changed from being primarily distributive in the beginning to primarily integrative toward the end of their negotiations.

\section{Implications}

The fact that cooperative groups achieved low joint sums, but were highly satisfied with their negotiations, may seem strange at first blush. After all, members of these groups were motivated to maximize their group outcomes and knew that they shared this goal with one another. As a result, they might be expected to establish a trusting environment, quickly and accurately exchange information, and reach optimal agreements with relative ease. However, this is not what happened. Instead, cooperative groups seemed to engage in satisficing-choosing the first acceptable agreement rather than looking for optimal agreements. The process analyses indicate that cooperative groups never became very integrative or very distributive. They may have lacked the energy needed to develop integrative agreements. Further research is needed to learn more about what goes on in cooperative groups, especially because our experiment failed to find a mediating effect of the negotiation process. Perhaps members of cooperative groups in our experiment yielded uncritically because they knew that everyone was cooperatively oriented. Another explanation may be derived from the motivated information processing perspective (De Dreu \& Carnevale, 2003; De Dreu, Koole, $\&$ Steinel, 2000). According to that perspective, joint outcomes in cooperative groups decrease when members have low rather than high epistemic motivation-when they have a low desire to develop and hold accurate and well-informed conclusions about the world. Being informed about the motivational orientations of one's opponents may lower epistemic motivation, because the desire to search for information about others is reduced. Future research might more closely examine the relationships among information about opponents, epistemic motivation, and resistance to yielding.

Individualistic groups achieved very high joint sums, but were not very satisfied with their negotiations. They also displayed an escalation of integrative behavior, and a de-escalation of distributive behavior, toward the end of those negotiations. This pattern is consistent with the idea that members of individualistic groups develop an enlightened self-interest: they initially exhibit distributive behavior, establishing firm positions and strong intentions. This is followed by a stage in which they still argue and hold onto their positions, but also share information and try to package issues. In the final stage, distributive activities drop dramatically and integrative activities begin to dominate. This pattern may be explained by the 'Perceived Feasibility Perspective' that extends Dual Concern Theory. This perspective predicts that contentious (distributive) behavior is an individualist's preferred strategy, '. . . but problem solving is a close second if the contentious approach appears infeasible or costly. Indeed, problem solving often seems the most viable way of pursuing one's own interests' (Pruitt \& Rubin, 1986, p. 35). We believe that knowing other group members share one's own individualistic orientation makes pressure tactics seem less effective, but further research is required to determine more closely what kind of processes lead individualistic groups to become more integrative. One explanation 
might be that individualistic groups more often reach temporary impasses (Harinck \& De Dreu, 2004). Future studies could also examine how individualistic groups can enhance subjective outcomes (such as satisfaction), so that they better match the other good outcomes that these groups achieve.

Finally, the mixed orientation groups did not achieve high joint sums, nor were they very satisfied with their negotiations. These groups seemed unable to develop integrative processes. Instead, their distributive processes grew stronger, leading to poor outcomes. These findings are consistent with Weingart et al. (2002), who found that mixed groups were more distributive than cooperative groups. Mixed groups may simply have problems finding a direction in which to go. Cooperators initially try to increase integrative activities in the group, while individualists constantly demand concessions, knowing that their opponents are cooperators and therefore likely to concede.

Our findings underscore the importance of understanding individualistic orientations and how groups with varying numbers of individualists behave and settle their conflicts. Individualists may be more context-sensitive than others. For example, cooperative groups achieve relatively good outcomes whether they consider issues simultaneously or sequentially, but individualistic groups do best when they negotiate issues simultaneously, rather than sequentially (Weingart et al., 1993). And cooperative groups negotiate well whether the structure of their task is symmetrical or asymmetrical, but individualistic groups do well only when their task structure is symmetrical (Beersma \& De Dreu, 2002). Other situational factors, such as time pressure (Carnevale \& Lawler, 1986) and visual access (Lewis \& Fry, 1977), also influence joint outcomes in individualistic dyads, but not in cooperative dyads. All of this suggests that cooperators are relatively contextinsensitive and behave similarly across a range of situations. In contrast, individualists adapt to situations, including their opponents' motivational orientations, more readily. This makes individualists more unpredictable, but does not necessarily make them worse negotiators. In fact, it was the individualistic groups in our experiment that negotiated the highest joint sums.

Finally, our findings also have some potential practical implications. When joint sums are important, negotiating groups should be composed of individualistic members who know each other's orientations. This implies that managers designing negotiation situations should encourage everyone to have individualistic orientations and make sure that these orientations are known. For example, managers would give instructions that are individualistic (as in our research) or use incentives that create individualistic orientations (e.g. individual-based rewards). And these instructions or incentives should be communicated to all participants. Although it may seem absurd to create individualistic conditions in order to enhance joint outcomes, it is important to remember that the main objective is to keep the parties from making inferior compromises. Individualistic orientations may stimulate group members to participate in an energetic search for integrative agreements. We thus advise managers to encourage 'energetic cooperation'-combining the energy stemming from individualistic orientations with the cooperative behavior stemming from recognition of how individual goals are best accomplished. Negotiators should back up individualistic motives with an understanding of the need for cooperation, or back up cooperative motives with an understanding of the need for energy. It is important to remember, however, that members of individualistic (and mixed) groups in our research were more dissatisfied with their negotiations than were members of cooperative groups. Because subjective outcomes such as satisfaction may affect later meetings of an ongoing group, stimulating members to be cooperatively oriented may be as important as stimulating them to be individualistic. Managers will have to decide which outcomes matter most, and design negotiation situations (if possible) accordingly.

\section{Limitations and future research}

Our research could be improved in at least three general ways. First, there is a need to examine 
the actual negotiation process more thoroughly. We used a post-negotiation questionnaire on which group members discussed process questions before they gave individual responses. One strength of this procedure is that it probably improves the quality of participants' reflections on the questions. Another strength is that we were able to examine the negotiation process in several phases, which led to the discovery that negotiation behavior changed significantly over time. Still, the question of why groups changed their behavior during their negotiations remains an issue for future research. For example, although the steady increase in integrative activities in the individualistic groups is consistent with enlightened selfinterest, the lack of mediating effects makes further research necessary to support this supposition. This should be coupled with a more rigorous process analysis. Also, we relied on retrospective memories of group members. Past research has shown that retrospective memories can indeed yield accurate information about past events during negotiations (Beersma \& De Dreu, 2002; De Dreu, Evers, Beersma, Kluwer, \& Nauta, 2001). But, memories can also be inaccurate at times. In future research, the actual behavior of negotiating groups could be recorded or observed directly. This would make it possible to examine our suggestions that cooperative groups are satisficing rather than optimizing, and that they have lower resistance to yielding than do groups with individualistic members. One could, for instance, examine time spent negotiating and the number of proposals put forward. Furthermore, the argument that temporary impasses help individualistic groups to achieve high joint sums could also be tested.

Second, our research examined the effects of motivational orientations when group members are aware of one another's orientationsa likely situation inside organizations and between organizations that negotiate frequently with each other. We did not, however, test the direct effect of having versus not having such information. It is worth noting in this regard that the negotiation task we used is identical to the task used by Schei and Rognes (2005). They examined the effects of motivational orientations when group members had no information about one another, but didn't find any differences in joint outcomes among groups with different compositions. Comparing the outcome scores for groups in their research with the relevant scores for our groups shows that their scores are similar to the scores of our cooperative and mixed groups. The composition that outperforms all others in both their work and ours is thus individualistic groups whose members are informed. It would be interesting to see if research designed to test the effects of information more directly could confirm the superiority of such groups. An extension of this research could be to include manipulations of group size and the awareness of motivational orientations in a single project.

Finally, we cannot rule out the possibility that some participants in our research changed their motivational orientation during the negotiations. However, this seems unlikely for two reasons. First, motivational orientations are different from, and more stable than, behavior (cf. Rhoades \& Carnevale, 1999). Although negotiators are expected to vary in how they behave to fulfill their goals, the goals themselves are likely to be firm. This is why we believe that members of individualistic groups became more integrative throughout the negotiation-they kept their individual goals, but changed their behavior from distributive to integrative when the latter behavior seemed to be the best way to accomplish those goals. Second, on our manipulation check measure, participants described their goals during the negotiation, but after it occurred. If the participants did not adopt the goals they were given, or changed their goals during the negotiation, then that would have been apparent in the manipulation check, yet there was no evidence of either problem.

In conclusion, the results of our research convey a paradox: cooperative groups are less likely to achieve integrative solutions than are groups whose members care only for their own outcomes. The irony is that having a goal of reaching a good solution was, in fact, harmful to the achievement of that goal. Groups negotiated the best solutions when their members had individualistic goals. Thus, Adam Smith's 
'invisible hand'-the metaphor explaining why individuals pursuing their own good can also promote the good of the community-has appeared in yet another arena. The common understanding of individualistic orientations as essentially detrimental to negotiations must therefore be reconsidered.

\section{References}

Bazerman, M. H., Mannix, E. A., \& Thompson, L. (1988). Groups as mixed-motive negotiations. In E. J. Lawler \& B. Markovsky (Eds.), Advances in group processes (Vol. 5, pp. 195-216). Greenwich, CT: JAI Press.

Beersma, B., \& De Dreu, C. K. W. (2002). Integrative and distributive negotiation in small groups: Effects of task structure, decision rule, and social motive. Organizational Behavior and Human Decision Processes, 87, 227-252.

Beersma, B., \& De Dreu, C. K. W. (2005). Conflict's consequences: Effects of social motives on postnegotiation creative and convergent group functioning and performance. Journal of Personality and Social Psychology, 89, 358-374.

Brett, J. M. (1991). Negotiating group decisions. Negotiation Journal, 7, 191-310.

Brett, J. M. (2001). Negotiating globally. San Francisco: Jossey-Bass.

Carnevale, P. J., \& Lawler, E. J. (1986). Time pressure and the development of integrative agreements in bilateral negotiations. Journal of Conflict Resolution, 30, 636-659.

Curhan, J. R., Elfenbein, H. A., \& Xu, H. (2006). What do people value when they negotiate? Mapping the domain of subjective value in negotiation. Journal of Personality and Social Psychology, 91, 493-512.

De Dreu, C. K. W., \& Carnevale, P. J. (2003). Motivational bases of information processing and strategy in conflict and negotiation. In M. Zanna (Ed.), Advances in experimental social psychology (pp. 235-293). New York: Academic Press.

De Dreu, C. K. W., Evers, A., Beersma, B., Kluwer, E. S., \& Nauta, A. (2001). A theory-based measure of conflict management strategies in the workplace. Journal of Organizational Behavior, 22, 645-668.

De Dreu, C. K. W., Giebels, E., \& Van de Vliert, E. (1998). Social motives and trust in integrative negotiation: The disruptive effects of punitive capability. Journal of Applied Psychology,

83, 408-422.

De Dreu, C. K. W., Koole, S., \& Steinel, W. (2000).

Unfixing the fixed-pie: Toward a motivated information-processing model of integrative negotiation. Journal of Personality and Social Psychology, 79, 975-987.

De Dreu, C. K. W., Weingart, L. R., \& Kwon, S. (2000). Influence of social motives on integrative negotiation: A meta-analytic review and test of two theories. Journal of Personality and Social Psychology, 78, 889-905.

Galinsky, A. D., Mussweiler, T., \& Medvec, V. H. (2002). Disconnecting outcomes and evaluations: The role of negotiator focus. Journal of Personality and Social Psychology, 83, 1131-1140.

George, J. M., \& Bettenhausen, K. (1990). Understanding prosocial behavior, sales performance, and turnover: A group-level analysis in a service context. Journal of Applied Psychology, 75, 698-709.

George, J. M., \& James, L. R. (1993). Personality, affect, and behavior in groups revisited: Comment on aggregation, levels of analysis, and a recent application of within and between analysis. Journal of Applied Psychology, 78, 798-804.

Harinck, F., \& De Dreu, C. K. W. (2004). Negotiating interests or values and reaching integrative agreements: The importance of time pressure and temporary impasses. European Journal of Social Psychology, 34, 595-611.

Holmes, M. E. (1992). Phase structures in negotiation. In L. L. Putnam \& M. E. Roloff (Eds.), Communication and negotiation (pp. 83-105). Newbury Park, CA: Sage.

James, L. R., Demaree, R. G., \& Wolf, G. (1984). Estimating within-group interrater reliability with and without response bias. Journal of Applied Psychology, 69, 85-98.

James, L. R., Demaree, R. G., \& Wolf, G. (1993). $\mathrm{r}_{\mathrm{wg}}$ : An assessment of within group interrater agreement. Journal of Applied Psychology, 78, 306-309.

Kelley, H. H., \& Stahelski, A. J. (1970). Social interaction basis of cooperators' and competitors' beliefs about others. Journal of Personality and Social Psychology, 16, 66-91.

Kenny, D. A., Kashy, D. A., \& Bolger, N. (1998). Data analysis in social psychology. In D. Gilbert, S. Fiske, \& G. Lindzey (Eds.), The handbook of social psychology (pp. 233-265). Boston: McGraw-Hill. 
Kramer, R. M. (1991). The more the merrier? Social psychological aspects of multiparty negotiations in organizations. Research on Negotiation in Organizations, 3, 307-332.

Lewis, S. A., \& Fry, W. R. (1977). Effects of visual access and orientation on the discovery of integrative bargaining alternatives. Organizational Behavior and Human Performance, 20, 75-92.

Mannix, E. A. (1994). Will we meet again? The effects of power, distribution norms, and scope of future interaction in small group negotiation. International Journal of Conflict Management, 5, 343-368.

Mannix, E. A., Thompson, L. L., \& Bazerman, M. H. (1989). Negotiation in small groups. Journal of Applied Psychology, 74, 508-517.

Olekalns, M., Brett, J. M, \& Weingart, L. R. (2003). Phases, transitions and interruptions: Modeling processes in multi-party negotiations. International Journal of Conflict Management, 14, 191-211.

Pruitt, D. G. (1983). Achieving integrative agreements. In M. H. Bazerman \& R. J. Lewicki (Eds.), Negotiation in organizations (pp. 35-50). London: Sage.

Pruitt, D. G., \& Carnevale, P. J. (1993). Negotiation in social conflict. Buckingham, UK: Open University Press.

Pruitt, D. G., \& Rubin, J. Z. (1986). Social conflict: Escalation, stalemate, and settlement. New York: McGraw-Hill.

Rhoades, J. A., \& Carnevale, P. J. (1999). The behavioral context of strategic choice in negotiation: A test of the dual concern model. Journal of Applied Social Psychology, 29, 1777-1802.

Rubin, J. (1991). Some wise and mistaken assumptions about conflict and negotiation. Journal of Social Issues, 45, 195-209.

Schei, V., \& Rognes, J. K. (2003). Knowing me, knowing you: Own orientation and information about the opponent's orientation in negotiation. International Journal of Conflict Management, 14, 43-59.

Schei, V., \& Rognes, J. K. (2005). Small group negotiation: When members differ in motivational orientation. Small Group Research, 36, 289-320.

Shapiro, D. L., \& Rognes, J. K. (1996). Can a dominating orientation enhance the integrativeness of negotiated agreements? Negotiation Journal, 12, 81-90.

Simon, H. (1957). Administrative behavior. New York: Free Press of Glencoe.
Ten Velden, F., Beersma, B., \& De Dreu, C. K. W. (2007). Majority and minority influence in group negotiation: The moderating effects of social motivation and decision rules. Journal of Applied Psychology, 92, 259-268.

Tripp, T. M., \& Sondak, H. (1992). An evaluation of dependent variables in experimental negotiation studies: Impasse rates and Pareto efficiency. Organizational Behavior and Human Decision Processes, 51, 272-295.

Weingart, L. R., Bennett, R. J., \& Brett, J. M. (1993). The impact of consideration of issues and motivational orientation on group negotiation process and outcome. Journal of Applied Psychology, 78, 504-517.

Weingart, L. R., Brett, J. M., \& Olekalns, M. (2002). Conflicting social motives in negotiating groups. Paper presented at the Academy of Management Conference, Denver.

Paper received 24 November 2006; revised version accepted 17 October 2007.

\section{Biographical notes}

VIDAR SCHEI is an associate professor of organizational behavior at the Norwegian School of Economics and Business Administration. His research interests include small groups, negotiation, and creativity, with an emphasis on how motivational, cognitive, and behavioral processes can facilitate high quality outcomes in mixed-motive interactions (e.g. negotiation, conflict, group decision making).

JØRN K. ROGNES is a professor of organizational behavior at the Norwegian School of Economics and Business Administration. He received his PhD from Northwestern University. His current research interest is conflict management with a particular focus on negotiation and mediation.

CARSTEN K. W. DE DREU is a professor of organizational psychology at the University of Amsterdam, the Netherlands. His research interests include judgment and decision making in strategic settings, with an emphasis on motivational, cognitive, and affective process underlying behavior in mixed-motive interdependence, social influence processes in small group settings, and creativity and innovation in groups. 